\title{
Studi Eksperimental dan Analisa Laju Keausan Roller pada Sistem Continously Variable Transmission (CVT) dengan Gerakan Reciprocating
}

\author{
Johan Ady Setyawan Indar Putra dan Yusuf Kaelani \\ Jurusan Teknik Mesin, Fakultas Teknologi Industri, Institut Teknologi Sepuluh Nopember (ITS) \\ Jl. Arief Rahman Hakim, Surabaya 60111 Indonesia \\ e-mail: y_kaelani@me.its.ac.id
}

\begin{abstract}
Abstrak - Sistem transmisi otomatis pada motor matik sudah banyak membahas mengenai roller. Seringnya pergantian roller yang diakibatkan aus, bahkan terkadang roller tersebut mengalami kerusakan perlu ditinjau dari kinematika pergerakan dari roller, laju keausan, dan umur pakai. Kinematika dari pergerakan roller dapat dianalisa dengan proyeksi gambar lintasan variator dan eksperimen yang dilakukan dengan menggunakan alat tribometer tipe pin on plate gerakan reciprocating tanpa pelumasan (Dry Sliding). Pengujian keausan 2 jenis roller yaitu round roller dan sliding roller dengan proyeksi gambar lintasan roller berisi tentang posisi dan kecepatan roller dalam rpm (engine) tertentu juga beban yang berbeda, Sedangkan eksperimen dilakukan dengan $\mathrm{L}=1500 \mathrm{~mm}$, 3 variasi kecepatan roller yang berbeda dan waktu yang ditentukan dari proyeksi gambar lintasan roller, yaitu $V_{1}=0,8944 \mathrm{~mm} / \mathrm{s}, \quad V_{2}=1,7152 \mathrm{~mm} / \mathrm{s}, \quad V_{3}=2,34 \mathrm{~mm} / \mathrm{s}, \quad t_{1}=11,255 \mathrm{~s}$, t2 $=11,86 \mathrm{~s}$, dan $t_{3}=12,003 \mathrm{~s}$. Didapatkan hasil Spesific Wear Rate pada round roller adalah $\mathbf{0 , 0 0 0 6 2 8 9 3 1 ,} 0,00127385$, dan 0,003950617, sedangkan Spesific Wear Rate pada sliding roller adalah 0,000457404, 0,000679012, dan 0,00305275. Grafik Spesific Wear Rate pada 2 jenis roller menunjukkan trendline naik sama seperti trendline Spesific Wear Rate linier dan ratarata pemakaian round roller bisa bertahan \pm 3 bulan dan sliding roller bisa bertahan \pm 6 bulan dalam penggunaan sepeda motor matik 6 jam sehari dalam satu tahun.
\end{abstract}

Kata Kunci - Sistem Transmisi Otomatis, Roller CVT, Keausan.

\section{PENDAHULUAN}

$\mathrm{T}$ RANSMISI OTOMATIS atau yang dikenal dengan sebutan Continuous Variable Transmision (CVT) adalah sistem transmisi otomatis tidak memakai gigi transmisi, tapi sebagai gantinya menggunakan dua buah pulley yang dihubungkan dengan sabuk (v-belt). Sistem CVT didesain agar pengendara dapat merasakan kenyamanan dalam berkendara karena tidak perlu menggunakan perpindahan gigi, hanya saja tinggal memutar gas untuk menambah kecepatan dan mengendorkan gas untuk mengurangi kecepatan.

Sepeda motor matik adalah sepeda motor yang menggunakan sistem CVT dalam kinerja sistem transmisi. Sepeda motor matik ini bekerja dengan putaran, jadi tidak akan dihasilkan tenaga seresponsif motor manual dan performa yang diberikan oleh sepeda motor matik ini dianggap kurang bertenaga. Untuk performa pada sepeda motor matik ini berkaitan dengan sistem CVT, karena sistem transmisi otomatis prinsip kerjanya menggunakan roller untuk mendapatkan gaya sentrifugal yang terpasang pada pulley. Roller merupakan salah satu komponen dari sistem CVT pada motor matik. Dengan menggunakan prinsip dasar dari gaya sentrifugal, maka roller sendiri difungsikan untuk menekan dinding dalam pulley primer sewaktu terjadi putaran tinggi. Kendala penyebab terjadinya kerusakan dari roller yaitu kurangnya perawatan pada sistem CVT, membuka tutup handle gas secara spontan, atau roller terkontaminasi oleh zatzat yang dapat mengganggu kinerja dari roller seperti debu, lumpur, dan lain-lain. Namun kasus yang sering terjadi di bengkel sepeda motor matik adalah pergantian roller yang diakibatkan aus.

Pada penelitian sebelumnya belum ada yang spesifik membahas tentang keausan yang terjadi pada roller. Kebanyakan membahas tentang variasi berat roller dan pengaruh perubahan berat roller terhadap performa dari sepeda motor matik. Oleh karena itu didalam penelitian ini penulis mencoba untuk menganalisa kinematika dari pergerakan roller,laju keausan yang terjadi pada roller, dan memprediksi umur pakai dari roller.

\section{URAIAN PENELITIAN}

\section{A. Sistem Transmisi Otomatis}

Transmisi otomatis adalah transmisi kendaraan yang pengoperasiannya dilakukan secara otomatis dengan memanfaatkan gaya sentrifugal. Transmisi yang digunakan yaitu transmisi otomatis " $\mathrm{V}$ " belt atau yang dikenal dengan CVT (Constantly Variable Transmission). CVT merupakan sistem transmisi daya dari mesin menuju ban belakang menggunakan sabuk yang menghubungkan drive pulley dengan driven pulley menggunakan prinsip gaya gesek. Puli penggerak / Puli Primer adalah komponen yang berfungsi mengatur kecepatan sepeda motor berdasarkan gaya sentrifugal yang dihasilkan oleh roller akibat adanya putaran engine, yang terdiri dari beberapa komponen yaitu dinding luar puli penggerak dan kipas pendingin, dinding dalam puli penggerak (moveable drive face), bushing/ bos puli, 6 buah roller, plat penahan, dan sabuk $V$-belt. Komponen puli primer dapat ditunjukkan pada gambar 1 dibawah ini. Sedangkan Puli yang digerakkan / Puli Sekunder adalah komponen yang berkesinambungan dengan puli primer dan juga terdapat beberapa komponen didalamnya, yaitu dinding luar puli 
sekunder, pegas pengembali, kampas kopling dan rumah kopling, dan dinding dalam puli sekunder. Komponen puli sekunder dapat ditunjukkan pada gambar 2 dibawah ini.

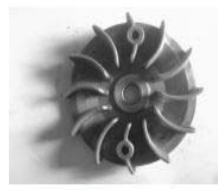

(a)

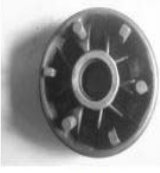

(b)

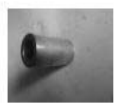

(c)

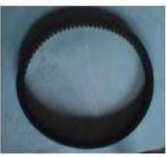

(f)

Gambar 1. Komponen Puli Primer [3]

Sedangkan Puli yang digerakkan / Puli Sekunder adalah komponen yang berkesinambungan dengan puli primer dan juga terdapat beberapa komponen didalamnya, yaitu dinding luar puli sekunder, pegas pengembali, kampas kopling dan rumah kopling, dan dinding dalam puli sekunder. Komponen puli sekunder dapat ditunjukkan pada gambar 2 dibawah ini.



(a)

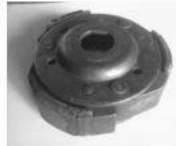

(c)

(d)

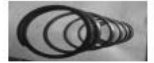

(b)



Gambar 2. Komponen Puli Sekunder [3]

\section{B. Analisa kinematika dari pergerakan roller}

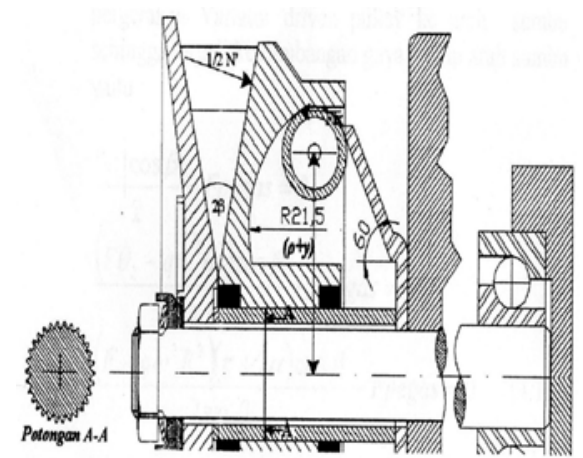

Gambar 3. Diagram benda bebas dari roller bergerak [8]

Untuk menghitung besarnya harga $\mathrm{Ft}$ pada tiap titik garis singgung kurva lingkaran, maka diperlukan sebuah proyeksi gambar sebagai berikut :

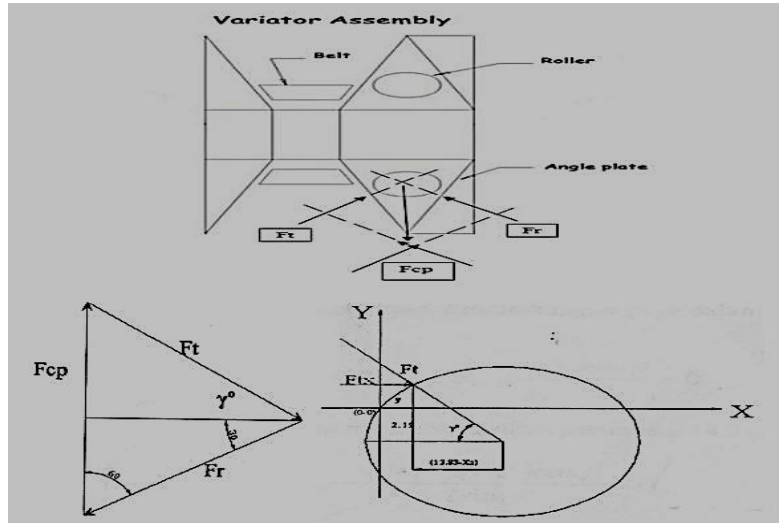

Gambar 4. Poligon Segitiga Gaya dan Kurva Lingkaran[8]

Berdasarkan gambar 4 dapat dilihat proyeksi gambar dari variator yang menjelaskan tentang vektor dalam bentuk poligon segitiga gaya dan kurva lingkaran yang menunjukkan arah posisi, sehingga didapatkan persamaan:

$\frac{F t}{\sin 60^{\circ}}=\frac{F c p}{\sin \left(30^{\circ}+\gamma^{\circ}\right)}$

$F t=\frac{F c p \times \sin 60^{\circ}}{\sin \left(30^{\circ}+\gamma^{\circ}\right)}$

Dimana Fcp adalah gaya sentrifugal

$F c p=m \omega^{2}(\rho+y)$

Dimana :

$\mathrm{M}=$ Massa roller

$\omega=$ Kecepatan sudut $\left(\frac{\mathrm{rad}}{\operatorname{detik}}\right)$

$\rho=$ Radius putar awal $=27 \mathrm{~mm}$

$F t=$ Gaya reaksi dari variator drive pulley

$\mathrm{Fr}=$ Gaya reaksi dari ramp plate

\section{Titik Lintasan Kecepatan pada Variator}

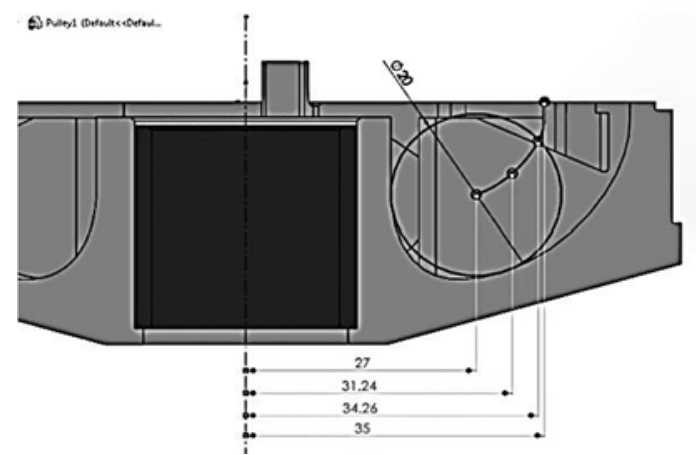

Gambar 5. Titik Lintasan Kecepatan pada Variator

Gambar 5 merupakan gambar roller yang bergerak dengan kecepatan tertentu pada lintasan variator dan radius yang berbeda-beda dititik lintasan kecepatan. Kecepatan roller terbagi atas 3 macam pada lintasan variator yaitu Kecepatan rendah, menengah, dan tinggi. Dari ketiga kecepatan tersebut memiliki radius yang berbeda - beda dan gaya sentrifugal yang dihasilkan roller pun juga berbeda. Maka persamaan yang didapatkan adalah : 


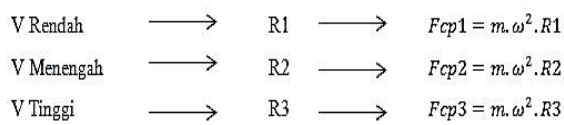

\section{Metode menghitung Laju Keausan}

Keausan (Wear) adalah kerusakan pada permukaan atau hilangnya material dari satu atau kedua permukaan benda padat pada saat terjadi gesekan, perputaran atau efek dari gerakan relatif antara satu sama lain.Keausan bukan merupakan sifat dasar material, melainkan respon material terhadap aksi mekanis (gesekan). Akibat negatif yang ditimbulkan adalah ketahanan (durability) dan kehandalan (reliability) dari benda yang aus akan berkurang karena perubahan dimensi dari benda tersebut.

Dalam mendeterminasikan keausan, teknik pengukuran yang berbeda dapat digunakan. Hal tersebut disebabkan oleh volume keausan, V, yang dapat diasumsikan merupakan fungsi dari sliding distance, $\mathrm{L}$, kekerasan dari material yang lebih lunak, H, pembebanan yang diberikan, $\mathrm{W}$, dan sliding velocity, $\tilde{\mathrm{V}}$ (persamaan 3 ).

$$
V=f(L, W, H, \tilde{V})
$$

Berdasarkan standar German DIN 50321, "Wearquantities", keausan dapat dideteksi dengan mengukur secara langsung kuantitas keausan, yaitu dengan mengukur wear coefficient yang didefinisikan sebagai berikut:

a. $K^{\prime}=\frac{\text { wear volume }}{\text { load.distance }}\left(\frac{\mathrm{mm}^{3}}{\mathrm{Nm}}\right)$

Atau dengan mengukur dimensionless Archard's wear coefficient yang didefinisikan sebagai berikut:

b. $K=\frac{\text { wear volume.hardness }}{\text { load.distance }}$

\section{METODE PENELITIAN}

Pengujian dalam penelitian ini didahului dengan Studi literatur mengenai sistem CVT (Continously Variable Transmission) pada sepeda motor matic khususnya pada bagian roller, mencari parameter operasional yang berkaitan dengan roller CVT, menganalisa kinematika pada roller, mengumpulkan data-data standar pengujian pada roller, melakukan pengujian dan perhitungan laju keausan pada roller, Menganalisa hasil laju keausan pada roller, Kemudian dibuat kesimpulan dari penyusunan tugas akhir ini. langkah langkah pada yang akan dilakukan untuk dalam pengujian adalah sebagai berikut :

\section{A. Menyiapkan Data-data pengujian.}

1) Data Spesifikasi motor honda vario 125 PGM-FI

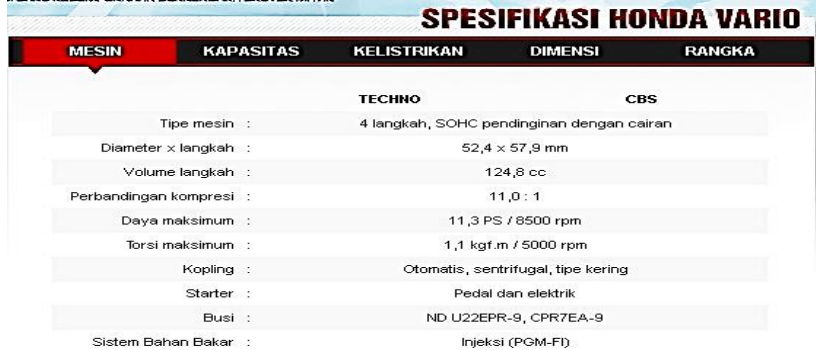

Gambar 6. Spesifikasi Honda Vario 125 PGM-FI

\section{2) Data Spesifikasi Roller Standar Vario PGM-FI SPESIFIKASI}

\begin{tabular}{|c|c|c|c|}
\hline & & & $\operatorname{an}: \mathrm{mr}$ \\
\hline & BAGIAN & STANDARD & BATAS SERVIS \\
\hline Lebar drive belt & & 22.0 & 21,0 \\
\hline Movable drive face & D.D. bushing & $23,989-24,052$ & 24,08 \\
\hline & D.L. boss & $23,960-23,974$ & 23,93 \\
\hline & D.L. weight roller & $19,92-20,08$ & 19,5 \\
\hline Kopling & Ketebalan lapisan kanvas & - & 20 \\
\hline & D.D. dutch outer & $1250-1252$ & 125.5 \\
\hline Driven pulley & $\begin{array}{l}\text { Panjang bebas pegas driven } \\
\text { face }\end{array}$ & 103,1 & @Q \\
\hline & DL boss driven face & $33965-33.985$ & 3394 \\
\hline & D.D. movable driven face & $34,000-34,025$ & 34,06 \\
\hline
\end{tabular}

Gambar 7. Spesifikasi roller standard 125 PGM-FI

3) Spesifikasi material Roller (Teflon/PTFE) standar Vario 125 PGM-FI

\begin{tabular}{|c|c|c|c|}
\hline Property & Value & \multicolumn{2}{|c|}{ Physical properties } \\
\hline Density & $2200 \mathrm{~kg} / \mathrm{m}^{3}$ & \multirow{6}{*}{$\begin{array}{l}\text { Melting point } \\
\text { Boiling point } \\
\text { Density near r.t. } \\
\text { when liquid, at m.p. } \\
\text { Heat of fusion } \\
\text { Heat of vaporization } \\
\text { Molar heat capacity }\end{array}$} & \multirow{2}{*}{$\begin{array}{l}\text { solid } \\
1357.77 \mathrm{~K}\left(1084,62^{\circ} \mathrm{C},\right. \\
\left.1984.32^{\circ} \mathrm{F}\right) \\
2835 \mathrm{~K}\left(2562^{\circ} \mathrm{C}, 4643^{\circ} \mathrm{F}\right)\end{array}$} \\
\hline Melting point & $600 \mathrm{~K}$ & & \\
\hline Thermal expansion & $112-125 \cdot 10^{-6} \mathrm{~K}^{-1}[22]$ & & $\begin{array}{l}2835 \mathrm{~K}(2562 \mathrm{C}, 4643 \mathrm{~F}) \\
8.96 \mathrm{~g} / \mathrm{cm}^{3} \\
8.02 \mathrm{~g} / \mathrm{cm}^{3}\end{array}$ \\
\hline Thermal diffusivity & $0.124 \mathrm{~mm}^{2} / \mathrm{s}$ & & \multirow{2}{*}{$\begin{array}{l}13.26 \mathrm{~kJ} / \mathrm{mol} \\
300.4 \mathrm{~kJ} / \mathrm{mol} \\
24.440 \mathrm{~J} /(\mathrm{mol} \cdot \mathrm{K})\end{array}$} \\
\hline Young's modulus & $0.5 \mathrm{GPa}$ & & \\
\hline Yield strength & $23 \mathrm{MPa}$ & & \multirow{2}{*}{$\begin{array}{l}16.5 \mu \mathrm{m} /(\mathrm{m} \cdot \mathrm{K})\left(\text { at } 25^{\circ} \mathrm{C}\right) \\
401 \mathrm{~W} /(\mathrm{m} \cdot \mathrm{K})\end{array}$} \\
\hline Bulk resistivity & $10^{16} \Omega \cdot m^{[24]}$ & \multirow{6}{*}{$\begin{array}{l}\text { Thermal expansion } \\
\text { Thermal } \\
\text { conductivity } \\
\text { Electrical resistivity } \\
\text { Magnetic ordering } \\
\text { Young's modulus } \\
\text { Shear modulus } \\
\text { Bulk modulus } \\
\text { Poisson ratio } \\
\text { Mohs hardness } \\
\text { Vickers hardness } \\
\text { Brinell hardness } \\
\text { CAS Number }\end{array}$} & \\
\hline Coefficient of friction & $0.05-0.10$ & & \multirow{3}{*}{$\begin{array}{l}16.78 \mathrm{nR} \cdot \mathrm{m}\left(\mathrm{at} 20^{\circ} \mathrm{C}\right) \\
\text { diamagnetic } \\
110-128 \mathrm{GPa} \\
48 \mathrm{GPa} \\
140 \mathrm{GPa}\end{array}$} \\
\hline Dielectric constant & $\varepsilon=2.1, \tan (\overline{0})<5(-4)$ & & \\
\hline Dielectric constant $(60 \mathrm{~Hz})$ & $\varepsilon=2.1, \tan (\delta)<2(-4)$ & & \\
\hline Dielectric strength $(1 \mathrm{MHz})$ & $60 \mathrm{MV} / \mathrm{m}$ & & $\begin{array}{l}0.34 \\
3.0\end{array}$ \\
\hline & & & $\begin{array}{l}343-369 \mathrm{MPa} \\
235-878 \mathrm{MPa} \\
7440-50-8\end{array}$ \\
\hline
\end{tabular}

Gambar 8. Spesifikasi material Roller (Teflon/PTFE) standar Vario 125 PGM-FI

B. Menyiapkan alat uji spesimen dan spesimen uji serta mengkalibrasi alat tersebut.

a. Alat uji yang digunakan untuk pengambilan data adalah Tribometer tipe pin on plate. Gambar 9 merupakan alat Tribometer tipe pin on plate beserta nama - nama bagian utamanva.

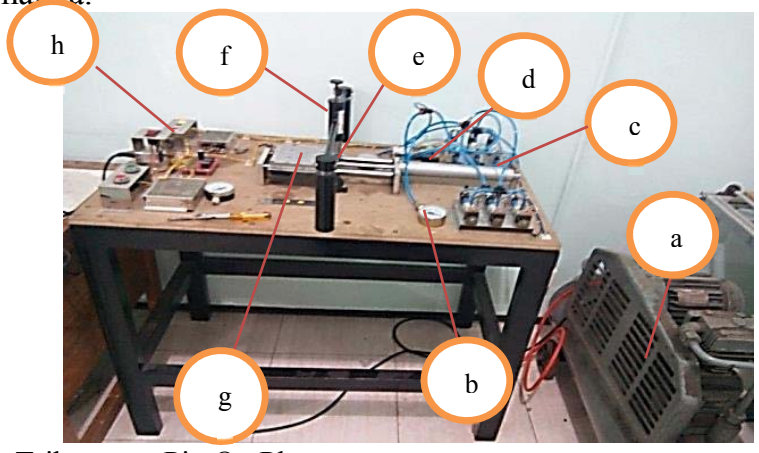

Gambar 9. Tribometer Pin On Plate

Keterangan:

- Nama-nama bagian Utama

a. Kompressor

b. Pressure Gauge

c. Sistem Pneumatik

d. Selenoid Valve

e. Spesimen Uji Roller

f. Tiang Pembebanan

g. Plate

h. Tombol Penghidup dan Tombol Pengatur Kecepatan alat 
b. Spesimen uji yaitu round roller dan sliding roller serta alat pencekam pada spesimen uji agar tidak bergerak kemana-mana sewaktu pengujian berlangsung. Spesimen uji dan alat pencekam dapat ditunjukkan pada gambar 10 dan gambar 11.
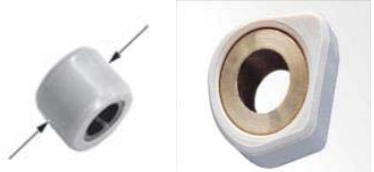

Gambar 10. Round roller dan sliding roller
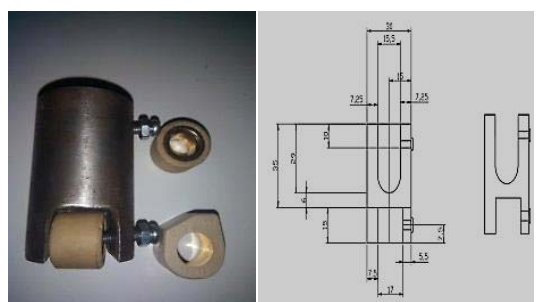

Gambar 11. Alat Pencekam Roller

c. Kalibrasi alat yang dilakukan adalah kalibrasi loadcell dan Kalibrasi kecepatan. Kalibrasi loadcell merupakan kalibrasi pegas dengan menggunakan berat badan dan posisi pegas berada didalam tiang pembebanan, sehingga pegas tinggal ditekan sesuai berat yang dibutuhkan. Sedangkan Kalibrasi Kecepatan dengan menggunakan Tachometer. Kalibrasi loadcell dan Kalibrasi Kecepatan dapat ditunjukkan pada gambar 12 dan gambar 13.
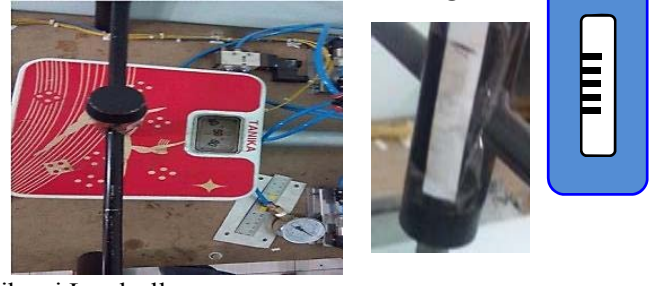

Gambar 12. Kalibrasi Loadcell

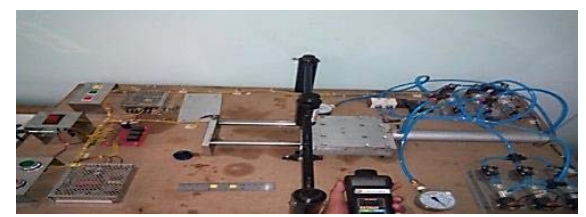

Gambar 13. Kalibrasi Kecepatan

Pada gambar 13 merupakan kalibrasi kecepatan alat uji dengan menggunakan tachometer dan didapatkan kecepatan pada alat uji yang dapat ditunjukkan pada tabel 1 .

\begin{tabular}{cc}
\multicolumn{2}{c}{ Tabel 1. Kalibrasi Speed Control } \\
\hline \hline Tombol & $\mathrm{V}(\mathrm{mm} / \mathrm{s})$ \\
\hline Kuning & 70 \\
Hijau & 130 \\
Merah & 230 \\
\hline \hline
\end{tabular}

\section{Menentukkan Perencanaan dari eksperimen}

Penelitian ini dilakukan pada round roller dan sliding roller dengan gerakan reciprocating (bolak- balik) menggunakan alat uji tribometer tipe pin on plate tanpa menggunakan pelumasan (dry sliding).Kemudian menentukkan variasi beban dan rasio kecepatan.Besarnya rasio kecepatan antara pin dan plate ditentukan berdasarkan kecepatan roller pada lintasan dengan kecepatan alat yang digunakan dan beban yang digunakan sesuai dengan perhitungan gaya sentrifugal yang dihasilkan roller. hasil yang didapat adalah laju keausan antara round roller dan sliding roller, sehingga perhitungan laju keausan dapat digunakan untuk prediksi umur pakai dari kedua roller tersebut. Pada gambar 14 adalah model dari perencanaan eksperimen yang akan dilakukan.

Dalam kondisi aktual round roller dan sliding roller bergerak naik - turun, sedangkan pada perencanaan eksperimen roller dicekam dan diberikan pembebanan kearah bawah dan plate yang digerakan oleh sistem pneumatik dengan arah gerakan reciprocating (bolak - balik ). Perencanaan eksperimen menyesuaikan dengan aktual putaran yang dihasilkan oleh motor, sehingga kecepatan pada motor dengan alat uji dibuat sebuah perbandingan rasio kecepatan dengan selang waktu yang ditentukan pada gerakan reciprocating (bolak - balik).

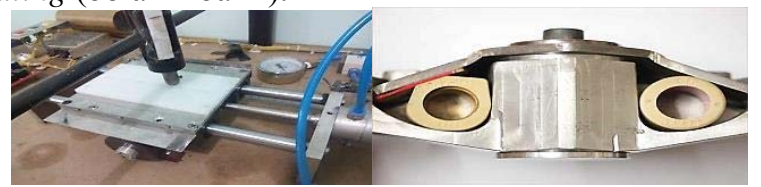

Gambar 14 Perencanaan ekperimen

Dalam perencanaan eksperimen pin on plate ini perlu memperhitungkan terlebih dahulu lamanya selang waktu yang dibutuhkan dengan rasio kecepatan motor yang telah ditentukan. Lamanya waktu pengujian dihitung dengan menggunakan formula berikut :

$t=\frac{L}{v}$

Keterangan :

$\mathrm{t}=$ waktu pengujian (s)

$\mathrm{L}=$ sliding distance $(\mathrm{m})$

$\mathrm{v}=$ Kecepatan $(\mathrm{m} / \mathrm{s})$

Sedangkan perencanaan eksperimen untuk pengujian keausan pada penelitian ini dapat dilihat pada Tabel 2.

\begin{tabular}{|c|c|c|c|c|c|c|c|}
\hline 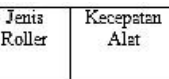 & $\begin{array}{l}\text { Masza } \\
\text { Awel } \\
(\mathrm{gr})\end{array}$ & $\begin{array}{l}\text { Meaza } \\
\text { Akhir } \\
\text { (gr) }\end{array}$ & $\frac{\Delta \mathrm{m}}{(\mathrm{gr})}$ & $\underset{(\mathrm{mm} / \mathrm{s})}{v}$ & $\underset{(\mathrm{mm})}{\mathrm{L}}$ & $\underset{\text { (menit) }}{\stackrel{t}{t}}$ & $\begin{array}{c}\text { Beban } \\
(\mathrm{kgg})\end{array}$ \\
\hline \multirow[b]{2}{*}{ Rendeh } & 13 & & & & \multirow[b]{2}{*}{1500} & & $\frac{1,3}{1,06}$ \\
\hline & 13 & & & & & & \begin{tabular}{|c|}
1,3 \\
1,06
\end{tabular} \\
\hline \multirow[b]{2}{*}{ Menengeh } & 13 & & & & \multirow[b]{2}{*}{1500} & & \begin{tabular}{|r|}
11,9 \\
5,4 \\
\end{tabular} \\
\hline & 13 & & & & & & \begin{tabular}{|c|}
11,9 \\
5,4
\end{tabular} \\
\hline \multirow{2}{*}{ Tinggi } & 13 & & & & \multirow{2}{*}{1500} & & \begin{tabular}{|c|}
35,1 \\
2,7
\end{tabular} \\
\hline & 13 & & & & & & \begin{tabular}{|c|}
35,1 \\
2,7 \\
\end{tabular} \\
\hline
\end{tabular}

Perubahan massa $(\Delta \mathrm{m})$ didapatkan dengan menimbang pin sebelum dilakukan pengujian dan kemudian ditimbang lagi menggunakan timbangan digital setelah dilakukan pengujian. $\mathrm{V}$ (Kecepatan roller), L(Panjang Lintasan), $\mathrm{t}$ (waktu pengujian). Untuk menghitung perubahan volume $(\Delta \mathrm{V})$ pin yang terjadi dengan menggunakan rumus seperti persamaan 7 dibawah ini :

$$
\Delta V=\frac{\Delta m}{\rho}
$$




\section{HASIL DAN DISKUSI}

Analisa Kinematika kecepatan roller pada lintasan ini sangat dibutuhkan sebagai acuan dari pengujian laju keausan roller yang terjadi pada saat engine (rpm) berputar. Untuk menganalisa kinematika kecepatan roller pada lintasan variator perlu mengetahui jarak, kecepatan roller pada rpm tertentu dan selang waktu yang dibutuhkan

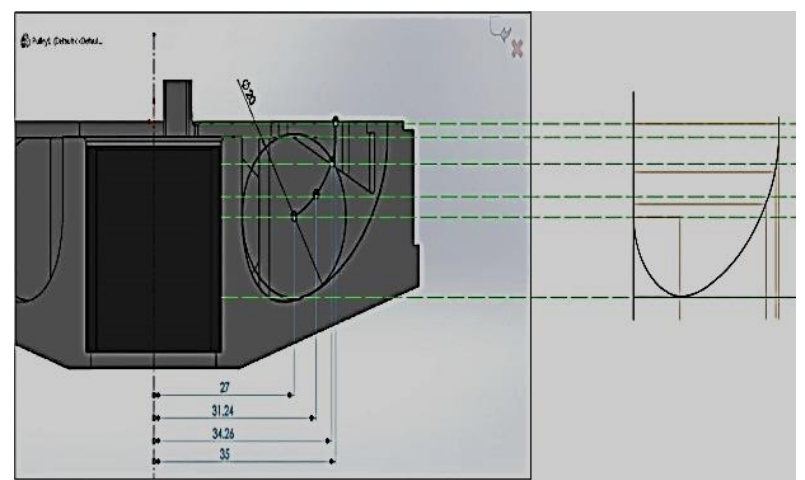

Gambar 15. Lintasan Variator yang berbentuk Kurvatur

Berdasarkan eksperimen mengendarai sepeda motor Honda Vario 125 PGM-FI dengan kecepatan 0-60 km/jam didapatkan waktu 6,03 detik, kecepatan $0-80 \mathrm{~km} / \mathrm{jam}$ didapatkan waktu 11,75 detik. Proyeksi pada gambar ditentukan sesuai hasil eksperimen dari mengendarai sepeda motor dan untuk menentukan nilai waktu dapat ditarik garis sumbu $\mathrm{x}$ dan $\mathrm{y}$ seperti pada gambar 16 .

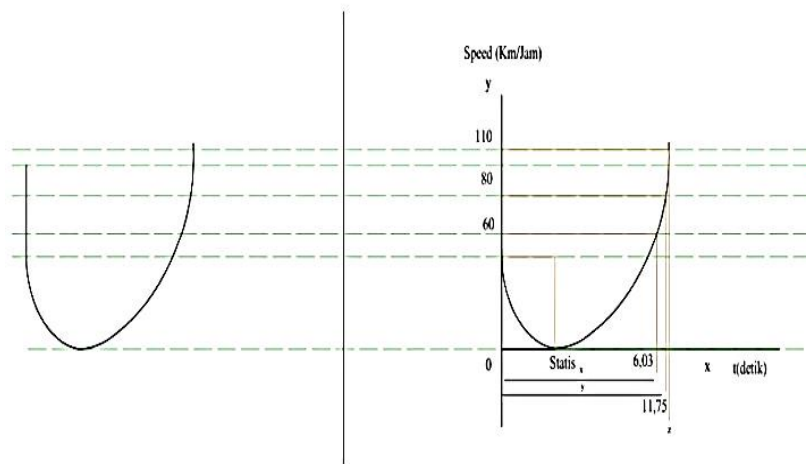

Gambar 16. Proyeksi gambar kurva

Dari Proyeksi gambar 16 dapat dibuat grafik perbandingan antara kecepatan dengan waktu melalui autocad, sehingga contoh perhitungan waktu dapat dituliskan sebagai berikut:

$$
\begin{aligned}
& \text { 1. } \frac{\text { Jarak } 0-11,75}{11,75}=\frac{\text { jarak } 0-x}{x} \\
& \mathrm{x}=\mathrm{t}_{1}=11,255 \text { detik } \\
& \text { 2. } \frac{\text { Jarak } 0-11,75}{11,75}=\frac{\text { jarak } 0-y}{y} \\
& \mathrm{y}=\mathrm{t} 2=11,86 \text { detik }
\end{aligned}
$$

3. $\frac{\operatorname{Jarak} 0-11,75}{11,75}=\frac{\text { jarak } 0-110}{z}$ $\mathrm{z}=\mathrm{t}_{3}=12,003$ detik

Sedangkan kecepatan didapatkan berdasarkan posisi roller yang diukur dari panjang kurva pada posisi tersebut dengan autocad, sehingga perhitungan kecepatan mengukur Arc length sesuai pada posisi roller di lintasan terlebih dahulu pada autocad yang dibagi dengan skala gambar. Gunakkan formula $t=\frac{L}{v} \quad$ untuk mendapatkan nilai kecepatan dan waktu pengujian.

1. Posisi titik $0-1$

$$
\begin{aligned}
& \frac{\text { Arc Length pada gambar }}{\text { skala gambar }}=\frac{3814,11}{378,89}=10,067 \mathrm{~mm} \\
& t=\frac{L}{v} \quad \mathrm{~V}_{1}=0,8944 \mathrm{~mm} / \mathrm{s}
\end{aligned}
$$

2. Posisi titik $0-2$

$\frac{\text { Arc Length pada gambar }}{\text { skala gambar }}=\frac{7701,31}{378,89}=20,352 \mathrm{~mm}$

$\mathrm{V}_{2}=1,7152 \mathrm{~mm} / \mathrm{s}$

3. Posisi titik 0-3

$\frac{\text { Arc Length pada gambar }}{\text { skala gambar }}=\frac{10640,35}{378,89}=28,083 \mathrm{~mm}$

$\mathrm{V}_{3}=2,34 \mathrm{~mm} / \mathrm{s}$

Berikut ini Hasil Gaya Sentrifugal Roller dan Pembebanan yang diterima dan data Hasil Percobaan pada tabel 3 dan 4 sedangkan Hasil Perhitungan dan Perhitungan umur pakai pada tabel 5 dan 6 .

Tabel 3. Data Hasil Perhitungan beban yang diterima (R1 dan R2)

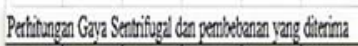



\begin{tabular}{l|l|l|l|l|l|l|l|l}
\hline 1 & 0,013 & 2200 & 1700 & 177,933 & 31,240 & 0,0312 & 47,340 & 69,687 \\
\hline
\end{tabular}



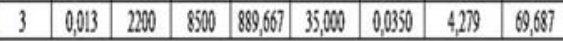

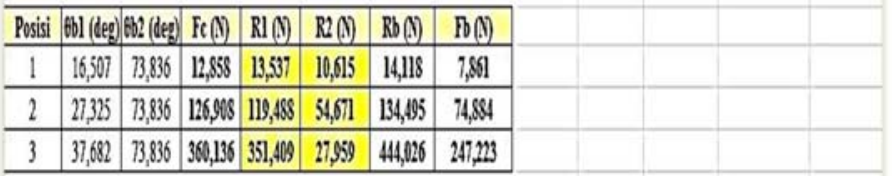

Sole:

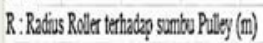

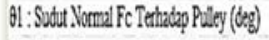

Q: Recopitan Sodu Pully (rdis)

82: Sobut. Tomal Fe Tethatep Ramp Pate (deg)

Fe: Goy Sertinivged (N)

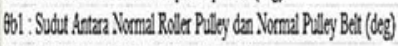

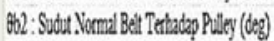

\begin{tabular}{|c|c|c|c|c|c|c|c|c|}
\hline $\begin{array}{l}\text { Jenis } \\
\text { Roller }\end{array}$ & $\begin{array}{c}\text { Kecepatan } \\
\text { Alat }\end{array}$ & $\begin{array}{c}\text { Massa } \\
\text { Awal } \\
\text { (gr) }\end{array}$ & $\begin{array}{l}\text { Massa } \\
\text { Akhir } \\
(\mathrm{gr})\end{array}$ & $\frac{\Delta \mathrm{m}}{(\mathrm{gr})}$ & $\begin{array}{c}\mathrm{V} \\
(\mathrm{mm} / \mathrm{s})\end{array}$ & $\begin{array}{c}\mathrm{L} \\
(\mathrm{mm})\end{array}$ & $\begin{array}{c}\mathrm{t} \\
\text { (menit) }\end{array}$ & $\begin{array}{c}\text { Beban } \\
(\mathrm{kg})\end{array}$ \\
\hline Round & \multirow[b]{2}{*}{ Rendah } & 13 & 12,978 & 0,022 & \multirow[b]{2}{*}{0,8944} & \multirow[b]{2}{*}{1500} & \multirow[b]{2}{*}{28} & 1,3 \\
\hline $\begin{array}{l}\text { Sliding } \\
\text { roller }\end{array}$ & & 13 & 12,984 & 0,016 & & & & $\begin{array}{l}, 00 \\
1,3 \\
106\end{array}$ \\
\hline $\begin{array}{l}\text { Round } \\
\text { roller }\end{array}$ & \multirow{2}{*}{ Menengah } & 13 & 12,773 & 0,227 & \multirow[b]{2}{*}{1,7152} & \multirow[b]{2}{*}{1500} & \multirow[b]{2}{*}{15} & 11,9 \\
\hline $\begin{array}{l}\text { Sliding } \\
\text { roller }\end{array}$ & & 13 & 12,879 & 0,121 & & & & $\frac{5}{54,9}$ \\
\hline $\begin{array}{l}\text { Round } \\
\text { roller }\end{array}$ & \multirow[b]{2}{*}{ Tinggi } & 13 & 12,648 & 0,352 & \multirow[b]{2}{*}{2,34} & \multirow[b]{2}{*}{1500} & \multirow[b]{2}{*}{11} & $\begin{array}{l}35,1 \\
27\end{array}$ \\
\hline $\begin{array}{l}\text { Sliding } \\
\text { roller }\end{array}$ & & 13 & 12,728 & 0,272 & & & & $\begin{array}{c}35,1 \\
2,7\end{array}$ \\
\hline
\end{tabular}

n: Kecrequen Pliley (mon)

R1:Gay . Vomd Roler Tethdep Plitey (I)

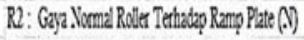

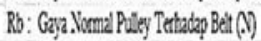

Po: Goya Tegrang Bat (D)

Tabel 4. Data Hasil Percobaan 
Tabel 5. Hasil Perhitungan

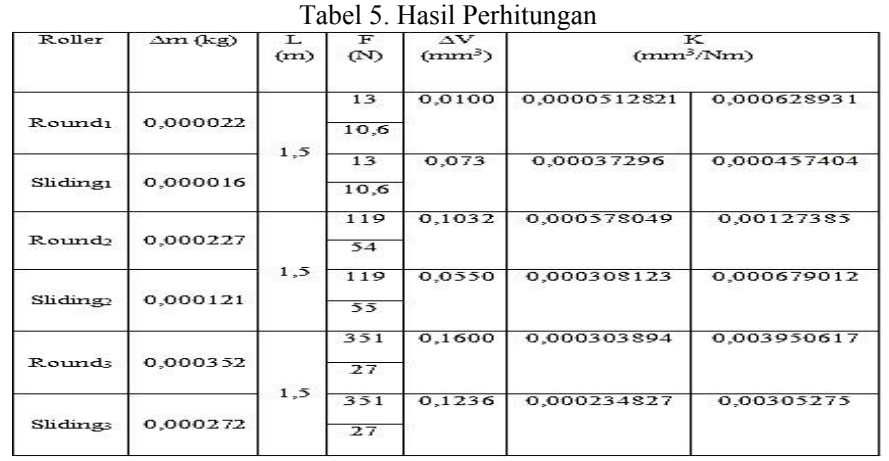

Tabel 6. Perhitungan Umur Pakai

\begin{tabular}{|c|c|c|c|}
\hline $\begin{array}{c}\text { Jenis Roller (Round } \\
\text { roller dan Sliding } \\
\text { roller) }\end{array}$ & $\begin{array}{c}\text { Pemakaian 6 } \\
\text { jam sehari } \\
\text { dalam satu } \\
\text { tahum }\end{array}$ & $\begin{array}{c}\text { Batas volume } \\
\text { roller yang } \\
\text { tergerus (Ad) }\end{array}$ & $\begin{array}{c}\text { Umur Pakai } \\
\text { (Tahun) }\end{array}$ \\
\hline $\mathrm{R}_{1}$ & 34,5600 & 29,4375 & 0,8518 \\
\hline $\mathrm{S}_{1}$ & 25,1345 & 29,4375 & 1,1712 \\
\hline $\mathrm{R}_{2}$ & 356,5964 & 29,4375 & 0,0826 \\
\hline $\mathrm{S}_{2}$ & 190,0800 & 29,4375 & 0,1549 \\
\hline $\mathrm{R}_{3}$ & 552,9600 & 29,4375 & 0,0532 \\
\hline $\mathrm{S}_{3}$ & 427,2873 & 29,4375 & 0,0689 \\
\hline
\end{tabular}

Berdasarkan tabel 3, 4, 5 dan 6 dapat dibuat grafik Spesific Wear Rate, yang mana Grafik menjelaskan 3 variasi kecepatan yang berbeda pada round roller dan sliding roller dengan jarak gesekan dijaga konstan dan pembebanan yang diberikan pada tiap kecepatan berbeda-beda dikarenakan adanya gaya sentrifugal. Grafik Spesific Wear Rate di gambar 17 trendline Spesific Wear Rate pada round roller dan sliding roller menunjukkan naik, dimana kedua roller bergerak dari kecepatan rendah menuju ke kecepatan tinggi. Berdasarkan dari grafik, trendline pada Spesific Wear Rate linier naik karena semakin tinggi kecepatan maka semakin besar laju keausan yang terjadi pada spesimen.

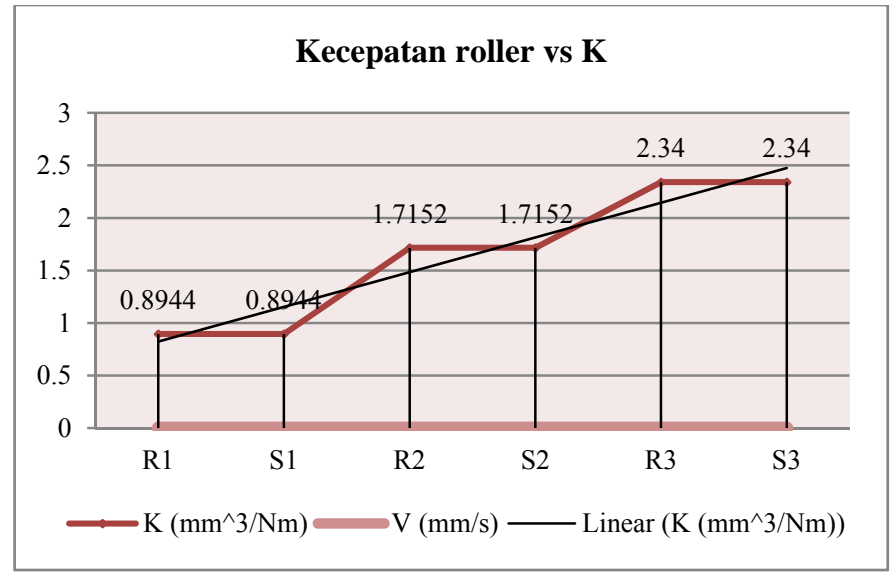

Gambar 17. Proyeksi gambar kurva

Pada gambar 18 merupakan nilai laju keausan terhadap 3 variasi kecepatan yang berbeda hasil dari laju keausan antara round roller dan sliding roller yang berbeda namun perbedaannya sangat kecil.

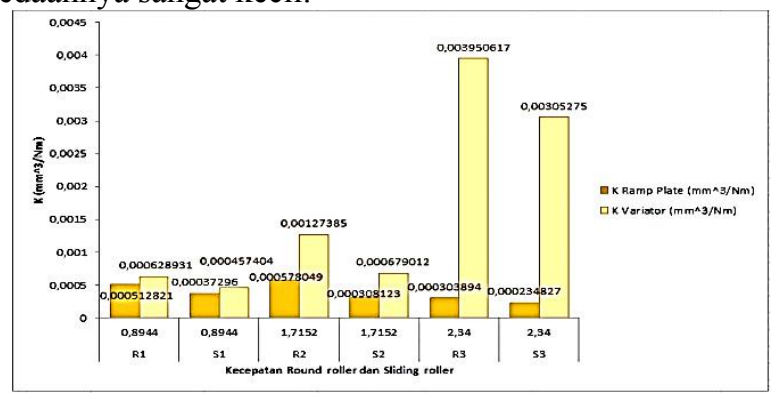

Gambar 18. Nilai laju keausan terhadap 3 variasi kecepatan

\section{KESIMPULAN}

Kesimpulan yang didapat dari studi eksperimental dan analisa laju keausan roller pada sistem CVT dengan gerakan reciprocating adalah :

1. kecepatan roller yang berbeda dan waktu yang ditentukan dari proyeksi gambar lintasan, yaitu $\mathrm{V}_{1}=$ $0,8944 \mathrm{~mm} / \mathrm{s}, V_{2}=1,7152 \mathrm{~mm} / \mathrm{s}, V_{3}=2,34 \mathrm{~mm} / \mathrm{s}, \mathrm{t}_{1}=$ $11,255 \mathrm{~s}, \mathrm{t} 2=11,86 \mathrm{~s}$, dan $\mathrm{t}_{3}=12,003 \mathrm{~s}$ pada alat tribometer tipe pin on plate dengan gerakan reciprocating didapatkan rata-rata nilai laju keausan yang berbeda pada roller tersebut. Hasil Spesific Wear Rate pada round roller adalah 0,000628931, 0,00127385, dan 0,003950617, sedangkan Spesific Wear Rate pada sliding roller adalah $0,000457404,0,000679012$, dan 0,00305275 . Grafik Spesific Wear Rate pada kedua jenis roller menunjukkan trendline naik sudah sesuai teori Spesific Wear Rate Linier ,dimana semakin tinggi kecepatan maka semakin besar nilai laju keausan yang terjadi.

2. Dari hasil perhitungan umur pakai roller, maka hasil pemakaian sepeda motor matik 6 jam sehari selama satu tahun didapatkan rata-rata perbandingan umur pakai, dimana round roller bisa bertahan \pm 3 bulan dan sliding rolle bisa bertahan \pm 4 bulan.

Dari berbagai kendala yang didapat pada saat pengujian, adapun saran yang diusulkan oleh penulis adalah Perlu adanya perawatan secara berkala dan pergantian komponen pada alat Tribometer tipe Pin On Plate di laboratorium Mekanika Benda Padat ITS-Surabaya agar alat dapat bekerja dengan baik saat melakukan pengujian dan dapat hasil yang optimal.

\section{DAFTAR PUSTAKA}

[1] Sutantra, I. N., \& Sampurno. (2010). Teknologi Otomotif Edisi Kedua. Surabaya: Intitut Teknologi Sepuluh Nopember.

[2] Jama, Julius (2008). Teknik Sepeda Motor.

[3] Rochadi, Fuad. 2007. Pembuatan Alat Peraga Transmisi Otomatis Sepeda Motor. Surakarta.

[4] Bhushan, Bharat. 2013. Principles and Applications of Tribology. New York : John Wiley \& Sons, INC.

[5] Mansyur, Ibrahim. 2012. Tribometer Actuator Mechanism Design PinOn-Plate with Driver Reciprocating Motion Eletropneumatic. Surabaya.

[6] Wijanarko. 2007. Analisa pengaruh perubahan massa roller penggerak variator pada Continously Variable Transmission (CVT) terhadap kinerja traksi pada sepeda motor yamaha mio. Surabaya.

[7] Ludema, C. Kenneth. 1996. Friction, Wear, Lubrication : A Textbook in Tribology. USA : CRC Press. 